\title{
MHD Boundary Layer Flow of Casson Fluid Past an Inclined Plate in the Presence of Soret/Dufour Effects, Heat Source and First-order Chemical Reaction
}

\author{
U. J. Das* \\ Department of Mathematics, Gauhati University, Assam-781014, India
}

Received 2 March 2021, accepted in final revised form 22 May 2021

\begin{abstract}
The main objective of this study is to investigate the effects of the Casson fluid parameter on an incompressible, magnetohydrodynamic boundary layer flow of a Casson fluid past a moving porous inclined plate in the presence of heat source and first-order chemical reaction. The governing partial differential equations are converted into ordinary differential equations using similarity transformation and then are solved numerically, adopting bv4pc method. The effects of relevant parameters on the velocity, temperature and concentration profiles are analyzed graphically. Also, tabular form is used to present skin friction, heat transfer and mass transfer. This investigation reveals that the Casson fluid parameter enhances the fluid velocity, skin friction and Sherwood number, while the Nusselt number decreases.
\end{abstract}

Keywords: Casson fluid; Magnetohydrodynamic; Soret number; Dufour number.

(c) 2021 JSR Publications. ISSN: 2070-0237 (Print); 2070-0245 (Online). All rights reserved. doi: http://dx.doi.org/10.3329/jsr.v13i3.52234 J. Sci. Res. 13 (3), 785-795 (2021)

\section{Introduction}

The heat and mass transfer of boundary layer flow with magnetohydrodynamic is of great theoretical interest because it has been applied in the engineering and chemical industry. The study of boundary layer flow over a continuous solid surface moving with constant speed was initiated by Sakiadis [1]. Raptis [2] studied the thermal radiation effect in a steady free convective flow in a porous medium bounded by a vertical infinite porous plate. Chamkha [3] studied the effect of heat source on MHD free convective flow in a vertical stretching surface. Makinde [4] studied the problem of free convection boundary layer flow with heat and mass transfer past a moving vertical permeable plate. Choudhury and Das [5] studied the problem of hydromagnetic convective flow of a visco-elastic fluid over a continuously moving vertical surface in the presence of uniform suction. Gangadhar and Reddy [6] analyzed the Newtonian fluid flow of MHD boundary layer flow in a moving vertical plate with suction. Das [7] presented the effects of visco-elastic parameter of a visco-elastic, electrically conducting fluid through a vertical plate.

\footnotetext{
*Corresponding author: utpaljyotidas@yahoo.co.in
} 
In several cases of simultaneous heat and mass transfer problems, the Soret and Dufour effects cannot be neglected [8]. Many authors have studied the effects of Soret and Dufour in various flow problems [9-15].

The study of the characteristic of non-Newtonian fluid with the porous medium is prevalent in many natural phenomena and polymer industries. The potential applications of such fluids exist in metallurgy, different nutrition process, penetrating process, and bioengineering maneuver [16]. One of the important non-Newtonian fluids that have been studied by many researchers is Casson fluid (e.g., tomato, honey, jelly, human blood, etc.) which shows shear thinning behavior. Casson [17] in 1959 initiated the study of Casson fluid behavior. The flow characteristics of Casson fluid have been developed by several authors [18-27].

The present paper extends the works of Gangadhar and Reddy [6] to Casson fluid, incorporating the impact of heat source parameter, Soret and Dufour effects on the magnetohydrodynamic boundary layer flow of Casson fluid past a moving inclined plate. MATLAB bvp4c method is used to obtain the solution. It is observed that the obtained results in the absence of Casson parameter, chemical reaction parameter, heat source parameter, Soret and Dufour effects are agreed with that of Gangadhar and Reddy [6].

\section{Mathematical Formulation}

Consider a steady two-dimensional magnetohydrodynamic boundary layer flow of Casson fluid with heat and mass transfer over a continuously moving porous inclined plate in the presence of heat source and first-order chemical reaction. The effects of Soret and Dufour are taken into consideration. All the fluid properties are assumed to be constant except for the density variations in the buoyancy force term of the momentum equation. Here, $X$-axis is considered along the direction of the plate, and $Y$-axis is perpendicular to it (Fig. 1). A uniform magnetic field of strength $B_{0}$ is applied normal to the plate, and it is assumed that the induced magnetic field is negligible. Under these assumptions, the governing equations describing the flow [6,20] are

$$
\begin{aligned}
& \frac{\partial U}{\partial X}+\frac{\partial V}{\partial Y}=0 \\
& U \frac{\partial U}{\partial X}+V \frac{\partial V}{\partial Y}=v\left(1+\frac{1}{\gamma}\right) \frac{\partial^{2} U}{\partial Y^{2}}+g \beta\left(T-T_{\infty}\right) \cos \alpha+g \beta_{1}\left(C-C_{\infty}\right) \cos \alpha- \\
& \frac{\mu}{\rho K_{1}} U-\frac{\sigma B_{0}^{2}}{\rho} U \\
& U \frac{\partial T}{\partial X}+V \frac{\partial T}{\partial Y}=\frac{\kappa}{\rho C_{p}} \frac{\partial^{2} T}{\partial Y^{2}}+\frac{Q_{0}}{\rho C_{p}}\left(T-T_{\infty}\right)+\frac{D_{m} K_{T}}{C_{S} C_{p}} \frac{\partial^{2} C}{\partial Y^{2}} \\
& U \frac{\partial C}{\partial X}+V \frac{\partial C}{\partial Y}=D_{m} \frac{\partial^{2} C}{\partial Y^{2}}-K_{r}^{\prime}\left(C-C_{\infty}\right)+\frac{D_{m} K_{T}}{T_{m}} \frac{\partial^{2} T}{\partial Y^{2}}
\end{aligned}
$$

with boundary conditions [6], 


$$
\begin{aligned}
& U=U_{0} X, V=V_{0}, T=T_{w}=T_{\infty}+A X, C=C_{w}=B X+C_{\infty} \text { at } Y=0 ; \\
& U \rightarrow 0, V \rightarrow 0, T \rightarrow T_{\infty}, C \rightarrow C_{\infty} \text { as } Y \rightarrow \infty,
\end{aligned}
$$

where $\gamma$ Casson fluid parameter $\alpha$ is the inclination of the plate with vertical and $Q_{0}$ is rate of heat source,

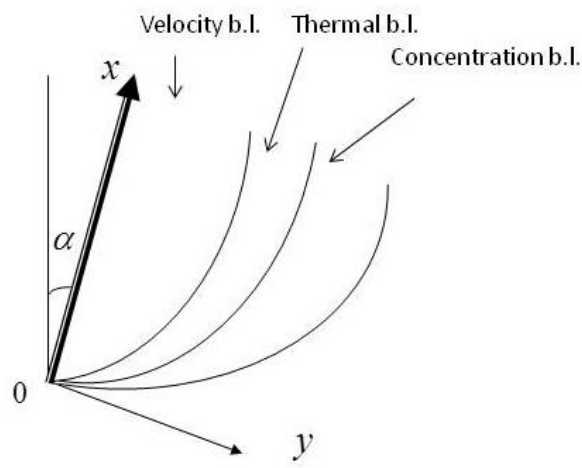

Fig. 1. Physical diagram.

A similarity solution of the equations (2)-(4) are obtained by introducing the following dimensionless functions

$$
\eta=Y \sqrt{\frac{U_{0}}{v}}, \psi=\sqrt{v U_{0}} f(\eta), \theta(\eta)=\frac{T-T_{\infty}}{T_{w}-T_{\infty}}, \varphi(\eta)=\frac{C-C_{\infty}}{C_{w}-C_{\infty}},
$$

with the stream function $\psi(X, Y)$ defined as $U=\frac{\partial \psi}{\partial Y}, V=-\frac{\partial \psi}{\partial X}$, so that the equation (1) is satisfied.

Using (7), the equations (2)-(4) reduces to the following dimensionless equations

$$
\begin{aligned}
& \left(1+\frac{1}{\gamma}\right) f^{\prime \prime \prime}+f f^{\prime \prime}-f^{\prime 2}+G r \cos \alpha \theta+G \cos \alpha \varphi-(H+K) f^{\prime}=0, \\
& \theta^{\prime \prime}+\operatorname{Pr} f \theta^{\prime}+Q \theta+\operatorname{Du} \operatorname{Pr} \varphi^{\prime \prime}=0, \\
& \varphi^{\prime \prime}+\operatorname{Sc} f \varphi^{\prime}-K_{r} S c \varphi+\operatorname{Sr} S c \theta^{\prime \prime}=0,
\end{aligned}
$$

with the boundary conditions

$$
\begin{aligned}
& f^{\prime}=1, f=-f_{w}, \theta=1, \varphi=1 \text { at } \quad \eta=0 ; \\
& f^{\prime}=0, \theta=0, \varphi=0 \quad \text { as } \eta \rightarrow \infty,
\end{aligned}
$$

Where the symbol prime (') denotes derivative with respect to $\eta G r=\frac{g \beta\left(T_{w}-T_{\infty}\right)}{X U_{0}^{2}}$ thermal Grashof number, $G c=\frac{g \beta_{1}\left(C_{W}-C_{\infty}\right)}{x U_{0}^{2}}$ is Grashof number for mass transfer, $H=\frac{\sigma B_{0}^{2}}{\rho U_{0}} \mathrm{is}$ Hartmann number, $K=\frac{v}{K_{1} U_{0}}$ is permeability parameter, $Q=\frac{Q_{0} v}{K U_{0}}$ is local heat source parameter, $K_{r}=\frac{K_{r}^{\prime}}{U_{0}}$ is local chemical reaction parameter, $\operatorname{Pr}=\frac{\mu C_{p}}{\kappa}$ is Prandtl number, 
$S c=\frac{v}{D_{m}}$ is Schmidt number, $S r=\frac{D_{m} K_{T}\left(T_{w}-T_{\infty}\right)}{v T_{m}\left(C_{w}-C_{\infty}\right)}$ is Soret number, $D u=\frac{D_{m} K_{T}\left(C_{w}-C_{\infty}\right)}{v C_{s} C_{p}\left(T_{w}-T_{\infty}\right)}$ is Dufour number, $f_{w}=-\frac{V_{0}}{\sqrt{v B}}$ is suction velocity.

\section{Method of Solution}

The equations (8)-(10) are coupled non-linear ordinary differential equations, and so their solution in closed form is not possible. To solve them, we convert the equations into firstorder differential equations with the help of the substitution

$$
F=y_{1}, F^{\prime}=y_{2}, F^{\prime \prime}=y_{3}, \theta=y_{4}, \theta^{\prime}=y_{5}, \varphi=y_{6}, \varphi^{\prime}=y_{7}
$$

With the help of the above substitution, the equations (8)-(10) together with boundary conditions (11)-(12), we get

$$
\begin{aligned}
& \left(1+\frac{1}{\gamma}\right) y_{3}^{\prime}=-y_{1} y_{3}+y_{2}^{2}-G r y_{4} \cos \alpha-G c y_{6} \cos \alpha+(H+K) y_{2} \text {, } \\
& (1+S r S c) y_{5}^{\prime}=-\operatorname{Pr} y_{1} y_{5}-Q y_{4}+D u \operatorname{Pr} S c\left(y_{1} y_{7}-K r y_{6}\right) \text {, } \\
& (1+\operatorname{SrSc}) y_{7}^{\prime}=\operatorname{SrSc}\left(Q y_{4}+\operatorname{Pr} y_{1} y_{5}\right)+\operatorname{Sc}\left(K_{r} y_{6}-y_{1} y_{7}\right)(1+\operatorname{SrSc}+\operatorname{SrScDu} \operatorname{Pr}) \text {, } \\
& \text { with } \\
& \eta=0: y_{2}=1, y_{1}=-f_{w}, y_{4}=1, y_{6}=1 \text {; } \\
& \eta \rightarrow \infty: y_{2}=0, y_{4}=0, y_{6}=0 \text {. }
\end{aligned}
$$

The above differential equations (13)-(15) are solved numerically under boundary conditions (16)-(17) by using bvp4c method of MATLAB.

\section{Results and Discussion}

The following value of the parameters are considered for numerical calculation $H=0.5, K=0.5, G r=1, G c=1, \gamma=1, K_{r}=0.5, D u=0.03, \quad Q=0.2, f_{w}=0.1, E c=$ $0.2, \operatorname{Pr}=0.72, S r=2, S c=0.62$, unless otherwise stated.

It is worth mention here that by setting $\gamma \rightarrow \infty, D u=0, S r=0, Q=0, K_{r}=0$, the velocity profiles are compared with the work of Gangadhar and Reddy [6] and are found in good agreement.

Figs. 2-6 represent the effect of the Casson fluid parameter $\gamma$, Hartmann number $H$, chemical reaction parameter $K_{r}$, heat source parameter $Q$, and Dufour/ Soret $D u$ / Srnumber on velocity profiles, respectively. The fluid velocity is highest at the inclined moving surface and gradually decreases to 0, far away from the plate. From Fig. 2, it is seen that the velocity of the fluid increases with the increasing values of the Casson fluid parameter for $\gamma=1$ to $\gamma=7$ through 3,5. Fig. 3 depicts that an increase in Hartmann number decreases the fluid velocity because the Lorentz force acts against the flow as the magnetic field is applied in the normal direction. Fig. 4 show that an increase in chemical reaction parameter reduces the fluid velocity. From Fig. 5, it is observed that the fluid velocity increase with increasing values of the heat source parameter. Assuming the product of the Dufour number and Soret number maintain a constant number 0.06, we 
observe from Fig. 6 that increasing values of Dufour number (or decreasing Soret number) decreases the velocity of the fluid.

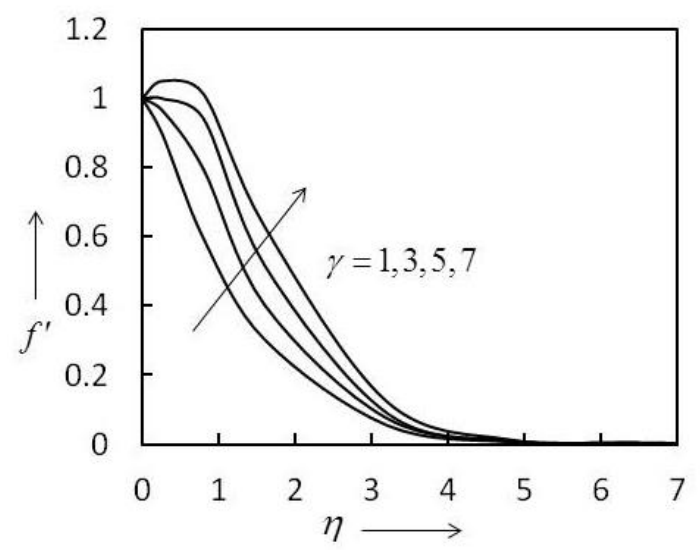

Fig. 2. Variation of velocity profile due to $\gamma$.

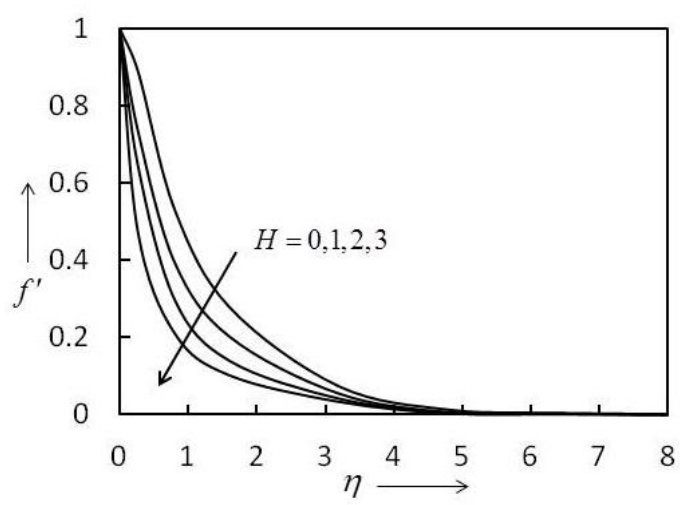

Fig. 3. Variation of velocity profile due to $H$.

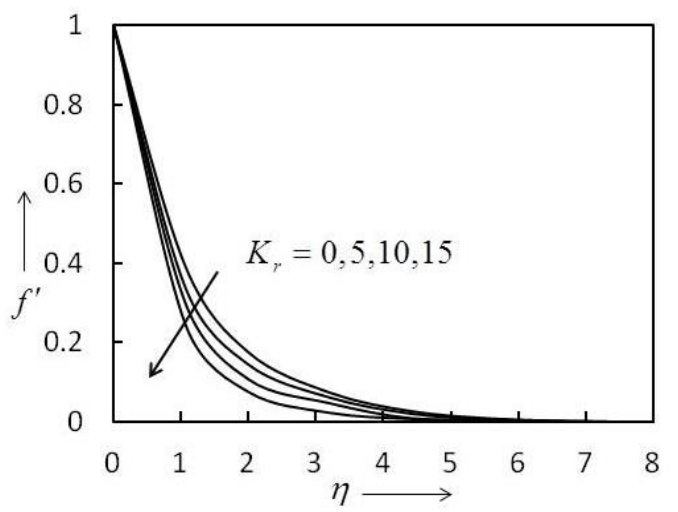

Fig. 4. Variation of velocity profile due to $K_{r}$. 


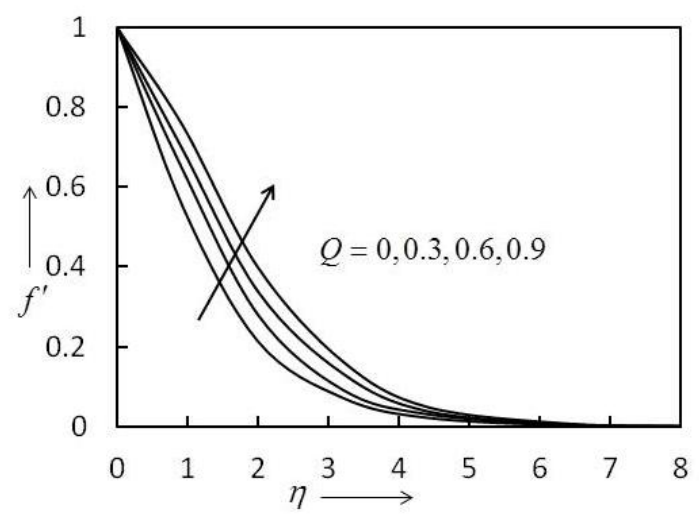

Fig. 5. Variation of velocity profile due to $Q$.

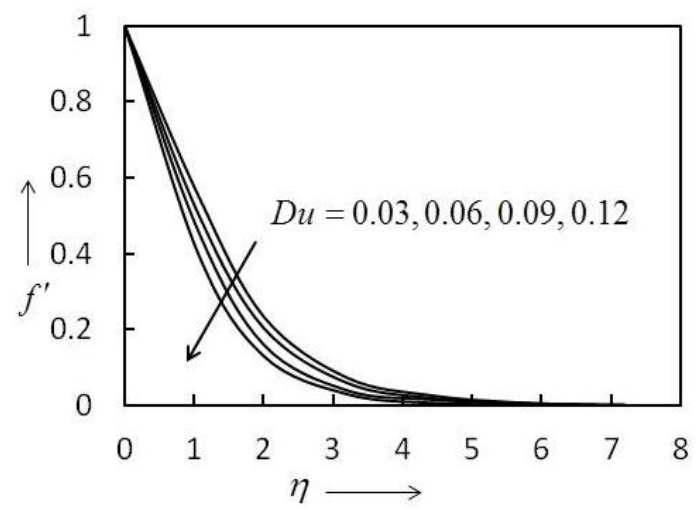

Fig. 6. Variation of velocity profile due to $\mathrm{Du}(\leftrightarrow$ orSr $)$.

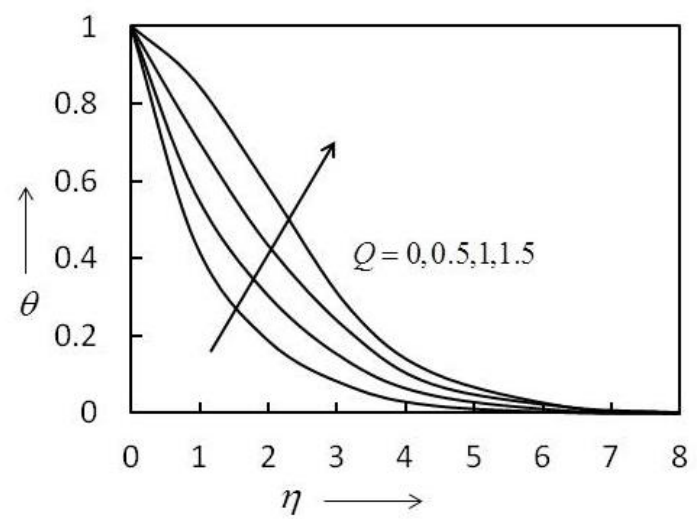

Fig. 7. Variation of velocity profile due to $Q$. 


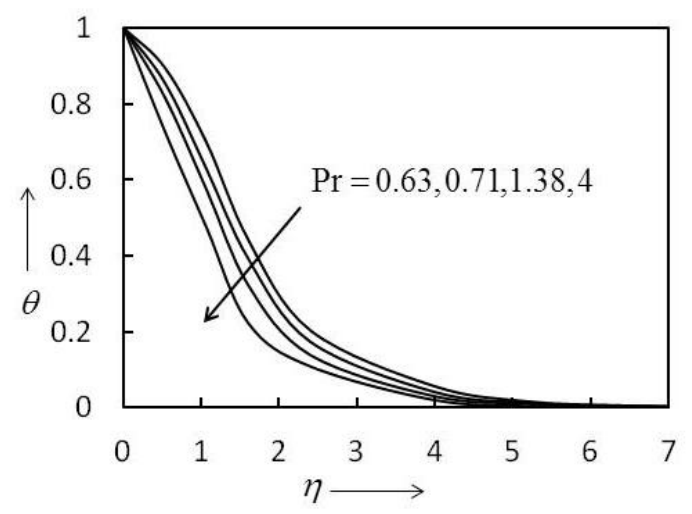

Fig. 8. Variation of temperature profile due to $\mathrm{Pr}$.

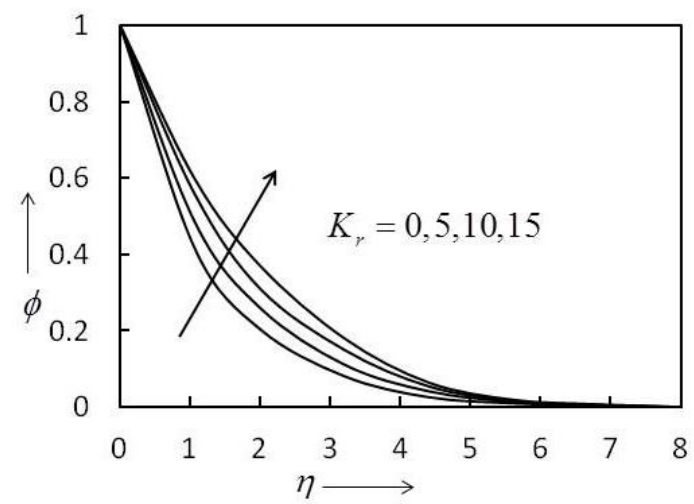

Fig. 9. Variation of concentration profile due to $\mathrm{Pr}$.

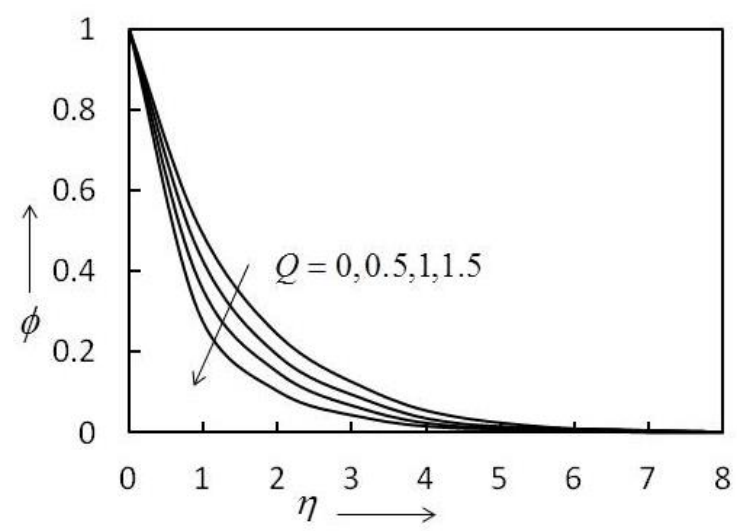

Fig. 10. Variation of concentration profile due to $Q$. 
The effects of the heat source parameter $(Q)$ and Prandtl number $(P r)$ on temperature profiles are presented in Figs. 7-8, respectively. From the Figs., it is observed that the temperature of the fluid increases with the increasing values of the heat source parameter, while it decreases with an increasing value of Prandtl number.

The effects of the chemical reaction parameter $\left(K_{r}\right)$ and heat source parameter $(Q)$ on temperature profiles are presented in Figs. 9-10, respectively. From the Figs., it is observed that the concentration profile increases with an increasing value of the chemical reaction parameter, while it decreases with an increasing value of the heat source parameter.

Table 1. Computational values of the skin friction $\left(-f^{\prime \prime}(0)\right)$, Nusselt number $\left(-\theta^{\prime}(0)\right)$, and Sherwood number $\left(-\varphi^{\prime}(0)\right)$.

\begin{tabular}{|l|l|l|l|l|l|l|}
\hline $\operatorname{Pr}$ & $K_{r}$ & $Q$ & $\gamma$ & $-f^{\prime \prime}(0)$ & $-\theta^{\prime}(0)$ & $-\varphi^{\prime}(0)$ \\
\hline 0.72 & 0.5 & 0.2 & 1 & 0.0273 & 0.3112 & 0.6165 \\
\hline 1.0 & 0.5 & 0.2 & 1 & 0.0741 & 0.4232 & 0.6071 \\
\hline 1.5 & 0.5 & 0.2 & 1 & 0.1584 & 0.5146 & 0.5845 \\
\hline 0.72 & 0 & 0.2 & 1 & 0.0128 & 0.2745 & 0.6436 \\
\hline 0.72 & 0.5 & 0.2 & 1 & 0.0273 & 0.3112 & 0.6165 \\
\hline 0.72 & 8 & 0.2 & 1 & 0.0782 & 0.4902 & 0.5972 \\
\hline 0.72 & 0.5 & 0 & 1 & 0.0765 & 0.5238 & 0.5612 \\
\hline 0.72 & 0.5 & 0.2 & 1 & 0.0273 & 0.3112 & 0.6165 \\
\hline 0.72 & 0.5 & 0.4 & 1 & 0.0094 & 0.2926 & 0.8257 \\
\hline 0.72 & 0.5 & 0.2 & 1 & 0.0273 & 0.3112 & 0.6165 \\
\hline 0.72 & 0.5 & 0.2 & 3 & 0.0182 & 0.3856 & 0.6096 \\
\hline 0.72 & 0.5 & 0.2 & 5 & 0.0105 & 0.4326 & 0.5744 \\
\hline
\end{tabular}

From Table 1, it is seen that the values of skin friction increase with the increasing values of Prandtl number, chemical reaction parameter, but reverse effect is observed with heat source parameter and Casson fluid parameter. The values of the Nusselt number increase with an increasing value of Prandtl number, chemical reaction parameter, and Casson fluid parameter, but it decreases for an increasing value of heat source parameter. Also, it is observed that the values of the Sherwood number decrease with an increasing value of Prandtl number, chemical reaction parameter and Casson fluid parameter, while it increases with an increasing value of heat source parameter and Hartmann number.

\section{Conclusion}

The above study leads to the following conclusion:

1. Casson fluid parameter and heat source parameter enhance the velocity of the fluid in the boundary layer, while Prandtl number, Hartmann number, chemical reaction parameter and Dufour number reduces the velocity of the fluid.

2. The temperature of the fluid in the boundary layer increases with the increasing values of the heat source parameter, but it reduces when the Prandtl number increases. 
3. Concentration profiles increase with the increasing values of Prandtl number, whereas it decreases with an increasing value of heat source parameter.

4. Casson fluid parameter and heat source parameter reduce skin friction, while Prandtl number and chemical reaction parameter enhance the skin friction.

5. Heat transfer coefficient profile can be increased by increasing Casson fluid parameter, Prandtl number and chemical reaction parameter, while heat source parameter helps to down.

6. The rate of mass transfer can be increased by increasing Casson fluid parameter, Prandtl number, and chemical reaction parameter.

\section{Nomenclature}

$A \quad$ stratification rate of the gradient of ambient temperature profile

$B \quad$ stratification rate of the gradient of ambient concentration profile

$B_{0} \quad$ strength of applied magnetic field

C concentration

$C_{p} \quad$ specific heat at constant pressure

$C_{s} \quad$ concentration susceptibility

$D_{m} \quad$ mass diffusivity

$\mathrm{Du} \quad$ Dufour number

$f_{w} \quad$ suction velocity

$-f^{\prime \prime}(0)$ skin friction

$g \quad$ gravitational acceleration

Gc Grashof number for mass transfer

$\mathrm{Gr}$ thermal Grashof number

$H \quad$ Hartmann number

$K \quad$ dimensionless permeability parameter

$K_{1} \quad$ dimensional permeability parameter

$K_{r} \quad$ chemical reaction parameter

$K_{r}^{\prime} \quad$ rate of chemical reaction

$K_{T} \quad$ thermal diffusion ratio

$\mathrm{Pr} \quad$ Prandtl number

$Q \quad$ heat source parameter

$Q_{0} \quad$ rate heat source parameter

Sc Schmidt number

$\mathrm{Sr} \quad$ Soret number

$T \quad$ temperature

$U \quad$ fluid velocity along $X-$ axis

$U_{0} \quad$ a constant

$V \quad$ fluid velocity along $Y-$ axis

$V_{0} \quad$ a constant 


\section{Greek letters}

$\begin{array}{ll}\alpha & \text { inclination of the plate with vertical } \\ \beta & \text { coefficient of heat transfer } \\ \beta_{1} & \text { coefficient of mass transfer } \\ \gamma & \text { Casson fluid parameter } \\ \eta & \text { similarity variable } \\ \theta & \text { non-dimensional temperature } \\ -\theta^{\prime}(0) & \text { Nusselt number } \\ \kappa & \text { thermal conductivity } \\ \rho & \text { density } \\ \sigma & \text { electrical conductivity } \\ v & \text { kinematic viscosity } \\ \varphi & \text { non-dimensional concentration } \\ -\varphi^{\prime}(0) & \text { Sherwood number }\end{array}$

\section{Subscript}

$\begin{array}{ll}w & \text { surface value } \\ \infty & \text { far away value from the plate }\end{array}$

\section{References}

1. B. C. Sakiadis, AIChE J. 7, 26 (1961). https://doi.org/10.1002/aic.690070108

2. A. Raptis, Int. Commun. 25, 289 (1998). https://doi.org/10.1016/S0735-1933(98)00016-5

3. A. J. Chamkha, Int. J. Heat and Fluid Flow 20, 84 (1999). https://doi.org/10.1016/S0142-727X(98)10032-2

4. O. D. Makinde, Int. Commun. Heat Mass Transfer 32, 1411 (2005). https://doi.org/10.1016/j.icheatmasstransfer.2005.07.005

5. R. Choudhury and U. J. Das, Int. J. Appl. Math Mech. 6, 1 (2010).

6. K. Gangadhar and N. B. Reddy, J. Appl. Fluid Mech. 6, 107 (2013).

7. U. J. Das, J. Eng. Phys. Therm. Phys. 89, 117 (2016).

8. E. R. G. Eckert and R. M. Drake, Analysis of Heat and Mass Transfer (New York: McGrawHill, 1972).

9. Z. Dursunkaya and W.M. Worek, Int. J. Heat Mass Transfer 35, 2060 (1992). https://doi.org/10.1016/0017-9310(92)90208-A

10. A. J. Chamkha and A. Ben-Nakhi, Heat Mass Transfer 44, 845 (2008). https://doi.org/10.1007/s00231-007-0296-x

11. D. Srinivasacharya and K, Kaladhar, Latin Am. Appl. Res. 41, 353 (2011).

12. S. M. M. EL-Kabeir, M. Modather, and A. M. Rashad, J. Modern Methods Numer. Math. 4, 10 (2013). https://doi.org/10.20454/jmmnm.2013.562

13. U. J. Das, Latin Am. Appl. Res. 49, 7 (2019). https://doi.org/10.52292/j.laar.2019.278

14. O. J. Fenuga, S. J. Aroloye, and S. O.Salawu, J. Sci. Res. 12, 485 (2020). https://doi.org/10.3329/jsr.v12i4.45551

15. S. H. Islam, P. Begum, and D. Sarma, J. Sci. Res. 13, 111 (2021). https://doi.org/10.3329/jsr.v13i1.48174

16. S. M. Arifuzzaman, M. S. Khan, A. Al-Mamun, S. K. Reza-E-Rabbi, P. Biswas, and I. Karim, J. King Saud University-Science 31, 1388 (2019). https://doi.org/10.1016/j.jksus.2018.12.009 
17. N. A. Casson, Flow Equation for Pigment Oil-Suspensions of the Printing Ink Type, in Rheology of Disperse Systems, ed. C. C. Mill (Pergamon Press, 1959) pp. 84.

18. S. Nadeem, R. U. Haq, and C. Lee, Sci. Iran 19, 1550 (2012). https://doi.org/10.1016/j.scient.2012.10.021

19. S. Mukhopadhyay, Chin. Phys. B 22, ID 074701 (2013). https://doi.org/10.1088/16741056/22/7/074701

20. S. Pramanik, Ain Shams Eng. J. 5, 205 (2014). https://doi.org/10.1016/j.asej.2013.05.003

21. C. K. Kirubhashankar, S. Ganesh, and A. M. Ismail, Appl. Math. Sci. 9, 345 (2015). https://doi.org/10.12988/ams.2015.411988

22. G. S. Seth and S. Sarkar, J. Mech. 31, 91 (2015). https://doi.org/10.1017/jmech.2014.71

23. Y. Immanuel, B. Pullepu, and C. K. Kirubhashankar, Appl. Math. Sci. 9, 1503 (2015). https://doi.org/10.12988/ams.2015.5153

24. C. S. K. Raju, N. Sandeep, and S. Saleem, Eng. Sci. Technol. Int. J. 19, 875 (2016). https://doi.org/10.1016/j.jestch.2015.12.004

25. J. V. R. Reddy, K. A. Kumar, V Sugunamma, and N Sandeep, Alex. Eng. J. 57, 1829 (2018).

26. S. K. Reza-E-Rabbi, S. M. Arifuzzaman, T. Sarkar, M. S. Khan, and S. F. Ahmmed, J. King Saud University-Sci. 32, 690 (2020). https://doi.org/10.1016/j.jksus.2018.10.017

27. S. K. Reza-E-Rabbi, S. F. Ahmmed, S. M. Arifuzzaman, T. Sarkar, and M. S. Khan, Eng. Sc. Technol. Int. J. 23, 605 (2020). https://doi.org/10.1016/j.jestch.2019.07.006 